\title{
A theoretical investigation of the organic carbon- microbial biomass relation in muddy sediments
}

\author{
Bernard P. Boudreau* \\ Dept. Oceanography, Dalhousie University, Halifax, Nova Scotia B3H 4J1, Canada
}

\begin{abstract}
A population/diagenetic model is developed to describe the behavior/dynamics of the microbial biomass in aquatic sediments. This model is analyzed in order to establish the dominant terms, i.e. processes, in that balance. The result of this analysis shows that production-removal processes, i.e. growth, death, grazing, transformation to inactive or active, etc., are essentially in balance to the best (lowest order) approximation, while all varieties of transport processes, i.e. motility, chemotaxis, bioturbation, burial, etc., contribute only higher order corrections to this balance. The balance between production-removal processes is shown to imply a linear relation between the size of the microbial biomass and the concentration of organic substrate, as advanced by Rublee (1982; Estuarine comparisons, Academic Press, p. 159-182), based on empirical evidence.
\end{abstract}

KEY WORDS: Organic matter $\cdot$ Microbial biomass $\cdot$ Modelling $\cdot$ Diagenesis

\section{INTRODUCTION}

The existence of a quantitative relation between the organic matter content of muddy sediments and the size of the microbial biomass has intrigued biogeochemists and benthic ecologists for some time. For example, Dale (1974) and Rublee (1982) both report significant linear correlations between these 2 variables; however, Bird \& Duarte (1989) argue that such correlations are potentially spurious. The nature of this criticism lies with the standardized mode of reporting biomass and carbon concentrations, and neither more measurements nor further statistical analyses will necessarily resolve this issue. A different approach, one based on independent theoretical considerations, can shed some light on the reality of this relation, and it is the aim of this paper to present such an analysis.

The size and evolution of a microbial population are governed by the interaction of various processes that can be formulated as a mathematical model. Models of this type have been employed to describe the dynamics of natural microbial populations in terrestrial

•E-mail: bpboudre@is.dal.ca aquifers, soils and rivers (e.g. Bazin et al. 1976, Hattori \& Hattori 1976, Hino 1981, Tan \& Bond 1995), but this approach has not, to this author's knowledge, been applied to aquatic sediments. The underlying principle behind these models is conservation of mass, and this is achieved by correct balancing of inputs, outputs and accumulations. Successful descriptions and predictions of the distribution of both dissolved and solid components, including organic matter, have been possible with this methodology (Berner 1971, 1980, Lerman 1977, 1978, 1979, Van Cappellen et al. 1993, Thibodeaux 1996, Van Cappellen \& Gaillard 1996, Boudreau 1997), and no reason exists to believe that it should not produce equally favorable results in dealing with sedimentary microbial biomass.

\section{THE MODEL}

The microbial biomass in a sediment is admittedly not a single quantity (variable). It is composed of various species (e.g. Nealson 1997) and of metabolically active and inactive organisms (e.g. Novitsky 1987). Differentiation of the different, largely bacterial species is probably not worthwhile for the purposes of this 
paper, but the total biomass can be divided into an active component of concentration $b_{\mathrm{a}}$ (in mass $C$ per unit volume of solid sediment) and an 'inactive' (not growing) component, $b_{d}$. In addition, the active cells may be found in the porewater and on the solid sediment surfaces. Rublee (1982) has argued that most cells adhere with varying degrees of tenacity to the solids, and only a small fraction is truly present in the solution. This paper follows Tan \& Bond (1995) by assuming that a linear equilibrium exists between free, $b_{\mathrm{f}}$ and surface-dwelling cells, for simplicity $b_{\mathrm{s}}$.

Dynamic mass balance for the components of the biomass at each point and time in a sediment is governed by differential equations for the surface active, porewater active and inactive cells, respectively (Lin \& Segel 1974, Berner 1980, Okubo 1980, Boudreau 1997)

$$
\underbrace{\frac{\partial \varphi_{\mathrm{s}} b_{\mathrm{s}}}{\partial t}}_{\begin{array}{c}
\text { Accumulation } \\
\text { with time }
\end{array}}=\underbrace{-\frac{\partial J_{\mathrm{s}}}{\partial x}}_{\begin{array}{c}
\text { Change of the } \\
\text { flux with depth }
\end{array}}+\underbrace{\sum \varphi_{\mathrm{s}} R_{\mathrm{s}}}_{\begin{array}{c}
\text { Net creation } \\
\text { or destruction }
\end{array}}
$$

and

$$
\begin{aligned}
\frac{\partial \varphi b_{\mathrm{f}}}{\partial t} & =-\frac{\partial J_{\mathrm{f}}}{\partial x}+\sum \varphi R_{\mathrm{f}} \\
\frac{\partial \varphi_{\mathrm{s}} b_{\mathrm{d}}}{\partial t} & =-\frac{\partial J_{d}}{\partial x}+\sum \varphi_{\mathrm{s}} R_{\mathrm{d}}
\end{aligned}
$$

where $t$ is time (years), $x$ is depth into the sediment relative to the sediment-water interface $(\mathrm{cm}), \varphi$ is porosity, $\varphi_{\mathrm{s}}$ is solid volume-fraction $(1-\varphi), J_{\mathrm{s}}, J_{\mathfrak{f}}$ and $J_{\mathrm{d}}$ are respectively the fluxes of surface-active, free-active and dead organisms at depth $x$ and time $t$ caused by the action of various transport processes $\left(\mathrm{g} \mathrm{C} \mathrm{cm}^{-2}\right.$ $\mathrm{Yr}^{-1}$ ), and $\Sigma R$ represents the net effect of all processes that create or destroy 1 of these model components ( $g$ $\mathrm{C} \mathrm{cm}^{-3} \mathrm{yr}^{-1}$ ). Simply stated, each equation says that if there is a change in the flux of a component with depth, this must be due to creation/loss by processes in $\Sigma R$ or net accumulation (either positive or negative) with time, i.e. the time-derivative term on the left-hand side of these equations. Eq. (3) indicates that the inactive cells are all treated as if they were attached, which is probably not true; however, the conclusions of this paper would not be altered by a significant free fraction of inactives, and the added simplicity from this assumption nutweighs any small inaccuracy from this source.

This paper's aim is to show that Eqs. (1) to (3) contain important information about the organic carbonmicrobial biomass relation; however, in order to extract this information, the exact forms of the fluxes, $J$, and the reactions, $\Sigma R$, in each of these equations must first be specified. Secondly, the relative importance of each term in the resulting equations must be calculated. Fortunately, a formal mathematical solution of these equations is not needed to achieve the stated goal.
In order to make the following development more transparent, the porosity will be treated as a constant This assumption is clearly wrong in most sediments, but its adoption has no effect whatsoever on the conclusions of this study.

\section{Flux terms}

All biomass, whether free or attached, appears to advect down the sediment column as more sediment is added by accumulation and the reference frame moves up (Berner 1980); this process creates an apparent downward flux, $J_{\mathrm{adv}}$, of organisms relative to the sediment-water interface. Such a term will appear in the balance equations for all microbial fractions.

Free-active microbes in the porewaters can also move/be moved as a result of Brownian motion (bm), motility (mo), chemotaxis (ct), bioturbation (bio) and hydrological dispersion (dis), each of which contributes a component to the flux of free biomass, $J_{f}$ i.e.

$$
J_{\mathrm{f}}=\left(J_{\mathrm{bm}}\right)_{\mathrm{f}}+\left(J_{\mathrm{mo}}\right)_{\mathrm{f}}+\left(J_{\mathrm{ct}}\right)_{\mathrm{f}}+\left(J_{\text {bio }}\right)_{\mathrm{f}}+\left(J_{\mathrm{djs}}\right)_{\mathrm{f}}+\left(J_{\mathrm{adv}}\right)_{\mathrm{f}}
$$

Following Hattori \& Hattori (1976), Corapcioglu \& Haridas (1984, 1985), Tan \& Bond (1995), and Boudreau (1997), Brownian motion is the random movement of small suspended particles due to the constant bombardment by water molecules, motility is the motion of microbes induced by their own 'random' movements, chemotaxis is the directed movement of organisms towards (or away from) a source of stimulation, e.g. food, bioturbation is the mixing of sediments by the actions of macrofauna (burrowing, ingestionegestion, plowing, etc., but not irrigation which is modelled differently, as described below), and hydrodynamic dispersion is a diffusionlike scattering which results when a flow occurs in a porous medium. The mathematical forms of these fluxes are displayed in Table 1, along with parameter value estimates. All but advection are diffusion-type relations.

Some entries in Table 1 deserve comment. In particular, muddy sediments generally have modest porewater velocities that do not engender any appreciable dispersion, i.e. small Peclet numbers (Boudreau 1997); consequently, $J_{\text {dis }}$ is made null by setting the dispersion coefficient $\left(D_{\text {dis }}\right)$ to zero. Secondly, the fraction of motile organisms, $\theta_{f}$ is probably small, as argued by Rublee (1982); however, the maximum influence of these transport terms will be obtained by setting this variable to unity.

Active microorganisms on sediment surfaces can move/be moved by burial, surface Brownian motion/diffusion (surf), motility, chemotaxis, and bioturbation, i.e.

$$
J_{\mathrm{s}}=\left(J_{\text {surf }}\right)_{\mathrm{s}}+\left(J_{\text {mo }}\right)_{\mathrm{s}}+\left(J_{\mathrm{cl}}\right)_{\mathrm{s}}+\left(J_{\text {bio }}\right)_{\mathrm{s}}+\left(J_{\mathrm{adv}}\right)_{\mathrm{s}}
$$


Table 1. Mathematical forms and parameter values for the flux terms in Eqs. (1) to (3)

\begin{tabular}{|c|c|c|c|c|}
\hline $\begin{array}{l}\text { Flux } \\
\text { (process) }\end{array}$ & Form & Parameter value & $\begin{array}{l}\text { Units of } \\
\text { parameter }\end{array}$ & Source \\
\hline $\begin{array}{l}\text { Advection in } \\
\text { porewater }\end{array}$ & $\left(J_{\text {udv }}\right)_{1}=\varphi u b_{1}$ & $10^{-4} \leq u<10^{6}$ & $\operatorname{cm} \mathrm{yr}^{-1}$ & Berner (1980) \\
\hline Advection of solids & $\left(J_{\text {ad } w}\right)_{\mathrm{s}}=\varphi_{\mathrm{s}} w b_{\mathrm{s}}$ & $10^{-4} \leq u<10^{0}$ & $\mathrm{~cm} \mathrm{yr}^{-1}$ & Berner (1980) \\
\hline Brownian motion & $\left(J_{\mathrm{bm}}\right)_{t}=-\varphi D_{\mathrm{bmm}} \frac{\partial b_{\mathrm{t}}}{\partial x}$ & $D_{\mathrm{bm}}=0.03$ & $\mathrm{~cm}^{2} \mathrm{yr}^{-1}$ & Segel et al. (1977) \\
\hline Motility & $\left(J_{\mathrm{mo}}\right)_{i}=-\varphi D_{\mathrm{mo}} \frac{\partial \theta_{1} b_{\mathrm{i}}}{\partial x}$ & $D_{\text {mo }} \leq 30$ & $\mathrm{~cm}^{2} \mathrm{yr}^{-1}$ & $\begin{array}{l}\text { Lovely \& Dahlquist (1975) } \\
\text { Segel et al. (1977) } \\
\text { Berg (1993) }\end{array}$ \\
\hline Chemotaxis & $\left(J_{c l}\right)_{1}=\varphi \theta_{1} b_{i} \frac{\left(D_{c t}\right)_{1}}{g} \frac{\partial g}{\partial x}$ & all $D_{\mathrm{cl}} \approx 2 D_{\mathrm{mo}}$ & $\mathrm{cm}^{2} \mathrm{yr}^{-1}$ & Rosen (1983) \\
\hline Porewater bioturbation & $\left(J_{\text {b1o }}\right)_{i}=-\varphi D_{\text {bio }} \frac{\partial b_{i}}{\partial x}$ & $10^{-2} \leq D_{\mathrm{b} 10} \leq 10^{1}$ & $\mathrm{~cm}^{2} \mathrm{yr}^{-1}$ & Berner (1980) \\
\hline Dispersion & $\left(J_{\text {dis }}\right)_{s}=-\varphi D_{\text {dis }} \frac{\partial b_{1}}{\partial x}$ & $D_{\mathrm{d} d \mathrm{~s}}=0$ & $\mathrm{~cm}^{2} \mathrm{yr}^{-1}$ & Tan \& Bond (1995) \\
\hline Surface diffusion & $\left(J_{\text {surt }}\right)_{s}=-\varphi_{s} D_{\text {surf }} \frac{\partial b_{s}}{\partial x}$ & $D_{\mathrm{surf}} \approx D_{\mathrm{bm}}$ & $\mathrm{cm}^{2} \mathrm{yr}^{-1}$ & Carberry (1976) \\
\hline Motility on solids & $\left(J_{m \mathrm{mo}}\right)_{\mathrm{s}}=-\varphi_{\mathrm{s}}\left(D_{\mathrm{mo}}\right)_{\mathrm{s}} \frac{\partial \theta_{\mathrm{s}} b_{\mathrm{s}}}{\partial x}$ & $\left(D_{\mathrm{mo}}\right)_{\mathrm{s}} \leq D_{\mathrm{mo}}$ & $\mathrm{cm}^{2} \mathrm{yr}^{-1}$ & $\begin{array}{l}\text { Analogy to Lovely \& } \\
\text { Dahlquist (1975) }\end{array}$ \\
\hline Chemotaxis on solids & $\left(J_{\mathrm{cl}}\right)_{h}=\varphi_{s} \theta_{s} b_{s} \frac{\left(D_{\mathrm{c}}\right)_{\mathrm{s}}}{g} \frac{\partial g}{\partial x}$ & $D_{\mathrm{cts}} \approx D_{\mathrm{cl}}$ & $\mathrm{cm}^{2} \mathrm{yr}^{-1}$ & Analogy to Rosen (1983) \\
\hline Bioturbation of solids & $\left(J_{\text {bio }}\right)_{s}=-\varphi_{s}\left(D_{\text {bio }}\right)_{s} \frac{\partial b_{s}}{\partial x}$ & $\left(D_{\mathrm{b} ı \mathrm{o}}\right)_{\mathrm{s}}=D_{\mathrm{b} \text { เo }}$ & $\mathrm{cm}^{2} \mathrm{yr}^{-1}$ & Boudreau (1997) \\
\hline \multicolumn{5}{|c|}{$\begin{array}{l}\text { Notes: } \\
u=\text { advective velocity of the porewater } \\
w=\text { burial velocity of solid sediment ( } u=w \text { if } \varphi=\varphi_{\mathrm{s}} \text { and with no externally forced hydrological flow } \\
D_{\mathrm{bm}}=\text { diffusion coeffcient for Brownian motion in porewater } \\
D_{\mathrm{mo}}=\text { diffusion coefficient for motility in porewater } \\
\theta_{\mathrm{f}}=\text { fraction of the free-dctive population that is motile/chemotactic (assumed to be a constant) } \\
\left(D_{\mathrm{mo}}\right)_{\mathrm{s}}=\text { diffusion coefficient for motility of microorganisms on sediment particle surfaces } \\
D_{\mathrm{surt}}=\text { Brownian motion diffusion coefficient on the surface of particles } \\
\theta_{\mathrm{s}}=\text { fraction of the surface-active population that is motile/chemotactic (assumed to be a constant) } \\
\left(D_{\mathrm{ct}}\right)_{\mathrm{f}}=\text { diffusion coefficient for chemotaxis of free microorganisms in porewater } \\
\left(D_{\mathrm{ct}}\right)_{\mathrm{s}}=\text { diffusion coefficient for chemotaxis of microorganisms on sediment particle surfaces } \\
D_{\mathrm{blo}}=\text { diffusion coefficient for bioturbation of microorganismsin porewater } \\
\left(D_{\mathrm{blo}}\right)_{\mathrm{s}}=\text { diffusion coefficient for bioturbation of microorganisms on sediment particles } \\
g_{1}=\text { concentration of the ith labile type of organic matter available to microorganisms for growth }\end{array}$} \\
\hline
\end{tabular}

The form and parameter values for these processes are also presented in Table 1. Diffusion coefficients for all these processes are set to their values in porewater; in reality, the surface Brownian motion, motility, and chemotaxis constants are probably smaller than the values in porewater, maybe significantly so, but no empirical data exists to resolve these conjectures; thus, $\left(D_{\mathrm{cl}}\right)_{\mathrm{s}}=\left(D_{c t}\right)_{\mathrm{f}} \equiv D_{\mathrm{ct}}$, etc., but also $\theta_{\mathrm{s}}=\theta_{\mathrm{f}} \equiv \theta$, etc.

In contrast, inactive organisms are treated as attached to solids (not a crucial assumption), such that they move only due to the processes of bioturbation and burial, i.e.

$$
J_{\mathrm{d}}=\left(J_{\mathrm{bio}}\right)_{\mathrm{d}}+\left(J_{\mathrm{adu}}\right)_{\mathrm{d}}
$$

and that these components are identical in form and parameter values to those associated with the active surface biomass, $\left(J_{\mathrm{bio}}\right)_{\mathrm{s}}$ and $\left(J_{\mathrm{adv}}\right)_{\mathrm{s}}$, respectively.

\section{Source-sink terms}

The sources and sinks represented by the $3 \Sigma R$ terms account for the appearance and removal of microor- 
ganisms at each depth and time and from each class defined above by biological and physical processes. The specific formulation of the growth/maintenance process into a mathematical statement is pivotal to the present analysis; consequently, some detail is needed in this respect. Microbial biomass can be created by net heterotrophy, photosynthesis and chemo-autotrophy. Net chemo-autotrophy is a process dominant in certain microbial mats and is not central to this study; therefore, it will be ignored hereafter. Net heterotrophy, i.e. oxidation of organic matter in geochemical terms, is the more common form of biomass creation in sediments, although photosynthesis by microphytobenthos is known where sufficient light is available.

The literature on modelling the growth of microbial populations is immense; however, much of it refers to microbial populations that are actually growing in size and not starved for food resources. Under such conditions the rate of growth/maintenance, $R_{\text {het }}$, can be described by an unstructured model of the generic form (Williams 1971, Humphrey 1972, Blanch 1981, Tan \& Bond 1995)

$$
R_{\text {het }}=y k_{\text {het }} b g
$$

where $k_{\text {het }}$ is a rate constant, $g$ is the concentration of the limiting nutrient (essentially equivalent to labile $C$ in sediments), $y$ is the yield for this reaction (i.e. mol $C$ incorporated in $b$ per mol $C$ in $g$ consumed), $b$ is a generic variable for $b_{\mathrm{f}}$ or $b_{\mathrm{s}}$, and the effect of oxidants or nutrients is ignored for the moment.

Eq. (7) creates a nonlinear response to additions of labile carbon because $b$ is also a function of labile $g$, and $b$ and $g$ are multiplied together in Eq. (7). If $g$ is altered, then the biomass will respond by some change, such that the rate, $R_{\text {het }}$, will be different than that calculated by the change in $g$ alone. Even if $g$ and $b$ are always in linear equilibrium, then a quadratic response is expected. The dynamics of carbon additions to sediments do not exhibit such a nonlinear response; specifically, Westrich \& Berner (1984) have provided clear evidence of a linear response of sedimentary heterotrophic rates to additions of labile carbon. Boudreau (1992) has provided a quasi-reaction mechanism that explains this response. As a result $R_{\text {het }}$ is more accurately described by the simpler expression

$$
R_{\text {hel }}=y k_{\text {het }} g
$$

Again, no overall dependence on oxidant concentration appears in this equation because total decomposition is being considered ${ }^{1}$. Only 1 type of labile organic

${ }^{1}$ This statement can be verified by considering Eqs. (4.199) to (4.203) in Boudreau (1997). By adding these equations and setting the Monod and inhibition constant equal for a given oxidant, the total rate of organic matter decay becomes oxidant independent matter is assumed to maintain the biomass in the upper 10 to $20 \mathrm{~cm}$ of sediments, and its reactivity must be on the order of a month or two in order to do so. This reactivity is consistent with that of fresh phytoplankton (e.g. Westrich \& Berner 1984).

The surface-active biomass, $b_{\mathrm{s}}$ is subject to growth by heterotrophy, possible photosynthesis, activation of inactive biomass, and is subject to loss by death, grazing, transformation to inactive, and attachmentdetachment, i.e. respectively,

$$
\begin{gathered}
\Sigma R_{\mathrm{s}}=\left(R_{\text {het }}\right)_{\mathrm{s}}+\left(R_{\text {pholo }}\right)_{\mathrm{s}}+\left(R_{\text {act }}\right)_{\mathrm{d}} \\
-\left(R_{\text {death }}\right)_{\mathrm{s}}-\left(R_{\text {graze }}\right)_{\mathrm{s}}-\left(R_{\text {trans }}\right)_{\mathrm{s}}+\left(R_{\mathrm{a}-\mathrm{d}}\right)_{\mathrm{s}}
\end{gathered}
$$

where the precise forms of each of these source-sink terms is to be found in Table 2. Death transfers organisms to the $g$ pool. While the active-free biomass in the porewater changes due to these same processes, irrigation can also have an effect. Irrigation is the biologically mediated exchange of water accomplished by tube-dwelling macrofauna (see Aller 1982, 1988). This exchange leads to 3-dimensional diffusion patterns that appear as a source-sink term in a 1-dimensional model (Boudreau 1984), i.e. $R_{\text {trrig, }}$ so that

$$
\begin{aligned}
& \Sigma R_{\mathrm{f}}=\left(R_{\text {het }}\right)_{\mathrm{f}}+\left(R_{\text {photo }}\right)_{\mathrm{f}}-\left(R_{\text {death }}\right)_{\mathrm{f}} \\
& -\left(R_{\text {graze }}\right)_{\mathrm{f}}-\left(R_{\text {trans }}\right)_{\mathrm{f}}-\left(R_{\mathrm{a}-\mathrm{d}}\right)_{\mathrm{f}}+R_{\mathrm{urng}}
\end{aligned}
$$

Finally, inactive biomass is increased by transformation from the active pool and decreased by death, grazing, and reactivation,

$$
\Sigma R_{\mathrm{d}}=\left(R_{\text {trans }}\right)_{\mathrm{d}}-\left(R_{\text {death }}\right)_{\mathrm{d}}-\left(R_{\text {graze }}\right)_{\mathrm{d}}-\left(R_{\mathrm{act}}\right)_{\mathrm{d}}
$$

The value for the yield in the heterotrophy terms is something of a question. Yields for various organic substrates are known, e.g. 0.5 for glucose (Lauffenburger 1983), and 0.29 to 0.68 for various other carbon sources (Gaudy \& Gaudy 1972, Corapcioglu \& Haridas 1984). Linley \& Newell (1984) and Blackburn (1987) present evidence that $y$ for natural microbial population acting on natural organic matter is much lower; consequently, a value of 0.2 is adopted, keeping in mind that the conclusions of this paper do not depend strongly on its exact value.

\section{Attachment-detachment equilibrium}

A discussion of attachment-detachment as an equilibrium process can be found in Tan \& Bond (1995) and is not repeated here. A linear relation (isotherm) is assumed to exist between the active biomass in the porewater and on the solid sediment, i.e.

$$
\mathrm{b}_{\mathrm{f}}=\left(K_{\mathrm{ads}} b_{\mathrm{s}} \varphi_{\mathrm{s}}\right) / \varphi
$$

where $K_{\text {ads }}$ is an appropriate adsorption coefficient, assumed to be a constant. Rublee (1982) has argued that 
Table 2. Mathematical forms and parameter values for the source and sink terms in Eqs (1) to (3)

\begin{tabular}{|c|c|c|c|c|}
\hline Reaction & Form & Parameter value & $\begin{array}{l}\text { Unit of } \\
\text { parameter }\end{array}$ & Source \\
\hline Heterotrophy & $R_{\text {het }}=y k_{\text {het }} g$ & $\begin{array}{c}k_{\text {het }} \approx 10 \\
y \approx 0.2\end{array}$ & $\begin{array}{c}\mathrm{yr}^{-1} \\
\mathrm{~mol} \mathrm{~mol}^{-1} \mathrm{C}\end{array}$ & $\begin{array}{l}\text { Westrich \& Berner (1984) } \\
\text { See body of text }\end{array}$ \\
\hline Photosynthesis & $R_{\text {photo }}=k_{\text {ptioto }} I b_{s}$ & $k_{\text {photo }} I \approx k_{\text {death }}$ & $\mathrm{yr}^{-1}$ & An assumption \\
\hline Death & $R_{\text {death }}=k_{\text {death }} b$ & $\begin{array}{l}k_{\text {death }} \approx 5.5 \\
k_{\text {death }} \approx 4.4\end{array}$ & $\begin{array}{l}y^{r^{-1}} \\
y^{-1}\end{array}$ & $\begin{array}{l}\text { Corapcioglu \& Haridas (1984) } \\
\text { Lauffenburger et al. (1981) }\end{array}$ \\
\hline Grazing & $R_{\text {graze }}=k_{\text {graze }} b$ & $k_{\text {graze }}=k_{\text {death }}$ & $\mathrm{yr}^{-1}$ & An assumption \\
\hline $\begin{array}{l}\text { Transformation } \\
\text { to dormant }\end{array}$ & $R_{\text {trans }}=k_{\text {trans }} b_{s}$ & $k_{\text {trans }} \approx k_{\text {death }}$ & $\mathrm{yr}^{-1}$ & An assumption \\
\hline $\begin{array}{l}\text { Transformation } \\
\text { to active }\end{array}$ & $R_{\mathrm{act}}=k_{\mathrm{act}} b_{\mathrm{d}}$ & $k_{\text {act }} \approx k_{\text {trans }} / 10$ & $\mathrm{yr}^{-1}$ & An assumption \\
\hline Irrigation & $R_{\text {irng }}=k_{\text {irrig }} b_{\mathrm{f}}$ & $k_{1, \Gamma \operatorname{gg}} \leq 200$ & $\mathrm{yr}^{-1}$ & Boudreau (1997) \\
\hline \multicolumn{5}{|c|}{$\begin{array}{l}\text { Notes: } \\
I=\text { intensity of light; since } k_{\text {photo }} \text { and } I \text { always appear as the combination } k_{\text {photo }} I \text {, they are treate } \\
\quad \text { author fully realizes that the variable } I \text { is strongly attenuated with depth in sediments, but } \\
\quad \text { outcome of this present study } \\
b=\text { generic biomass concentration that can represent } b_{\mathrm{d}}, b_{\mathrm{f}} \text { or } b_{\mathrm{d}} \text { as appropriate } \\
k_{\text {act }} \approx k_{\text {trans }} / 10 \text { in order to be consistent with the idea that most of the live biomass is dormant } \\
{ }^{a} \text { Assumptions are discussed in the text }\end{array}$} \\
\hline
\end{tabular}

most of the biomass is adsorbed; therefore, $K_{a d s}$ is a relatively small number dimensionless number, i.e. $<1$. Note that $K_{\text {ads }}$ is the inverse of the adsorption coefficient as it normally defined, e.g. Tan \& Bond (1995), but using this form leads to cleaner, easier to read equations.

\section{Final equations}

Substitution of the forms in Tables $1 \& 2$ and assuming constant porosity produces the new equations

$$
\begin{aligned}
& \frac{\partial b_{\mathrm{s}}}{\partial t}=\left(D_{\mathrm{bm}}+\theta D_{\text {mo }}+D_{\text {bio }}\right) \frac{\partial^{2} b_{\mathrm{s}}}{\partial \mathrm{x}^{2}}-\theta D_{\mathrm{ct}} \frac{\partial}{\partial x}\left(\frac{b_{\mathrm{s}}}{g} \frac{\partial g}{\partial x}\right) \\
& -w \frac{\partial b_{\mathrm{s}}}{\partial x}+\left(1-K_{\mathrm{ads}}\right) y k_{\text {het }} g+k_{\mathrm{act}} b_{\mathrm{d}} \\
& +\left(k_{\text {photo }} I-k_{\text {death }}-k_{\text {graze }}-k_{\text {trans }}\right) b_{\mathrm{s}}+\frac{R_{\mathrm{a}-\mathrm{d}}}{\varphi_{\mathrm{s}}} \\
& \frac{\partial b_{\mathrm{f}}}{\partial t}=\left(D_{\mathrm{bm}}+\theta D_{\text {mo }}+D_{\text {bıo }}\right) \frac{\partial^{2} b_{\mathrm{s}}}{\partial x^{2}}-\theta D_{\mathrm{ct}} \frac{\partial}{\partial x}\left(\frac{b_{\mathrm{f}}}{g} \frac{\partial g}{\partial x}\right) \\
& -w \frac{\partial b_{\mathrm{f}}}{\partial x}+\frac{K_{\text {ads }} \varphi_{\mathrm{s}}}{\varphi} y k_{\text {het }} g \\
& +\left(k_{\text {photo }} I-k_{\text {death }}-k_{\text {graze }}-k_{\text {trans }}-k_{\text {rחigg }}\right) b_{\mathrm{f}}-\frac{R_{\mathrm{a}-\mathrm{d}}}{\varphi}
\end{aligned}
$$

and

$$
\begin{aligned}
& \frac{\partial b_{\mathrm{d}}}{\partial t}=D_{\text {bio }} \frac{\partial^{2} b_{\mathrm{d}}}{\partial \mathrm{x}^{2}}-w \frac{\partial b_{\mathrm{d}}}{\partial x}+k_{\text {trans }}\left(b_{\mathrm{s}}+\frac{\varphi b_{\mathrm{f}}}{\varphi_{\mathrm{s}}}\right) \\
& -\left(k_{\text {death }}+k_{\text {graze }}+k_{\text {act }}\right) b_{\mathrm{d}}
\end{aligned}
$$

Eqs. (13) \& (14) still contain the attachment-detachment rate terms that are technically undefined, i.e. we have assumed the equilibrium given by Eq. (12). This indeterminacy is resolved by adding Eqs. (13) \& (14) and substituting Eq. (12) in order to obtain equations solely for $b_{\mathrm{s}}$ and $b_{\mathrm{d}}$, (e.g. see Berner 1980 , Chapter 4)

$$
\begin{aligned}
& \frac{\partial b_{\mathrm{s}}}{\partial t}=\left(D_{\mathrm{bm}}+D_{\mathrm{blo}}+\theta D_{\mathrm{mo}}\right) \frac{\partial^{2} b_{\mathrm{s}}}{\partial x^{2}}-\theta D_{\mathrm{ct}} \frac{\partial}{\partial x}\left(\frac{b_{\mathrm{s}}}{g} \frac{\partial g}{\partial x}\right) \\
& -w \frac{\partial b_{\mathrm{s}}}{\partial x}+\frac{y k_{\text {het }} g}{\left(1+K_{\mathrm{ads}}\right)}+k_{\mathrm{act}} b_{\mathrm{d}} \\
& +\left(k_{\mathrm{pholo}} I-k_{\text {death }}-k_{\text {graze }}-k_{\text {trans }}\right) b_{\mathrm{s}}-\frac{K_{\mathrm{ads}}-k_{\text {irrig }} b_{\mathrm{s}}}{\left(1+K_{\mathrm{ads}}\right)}
\end{aligned}
$$

and

$$
\begin{aligned}
& \frac{\partial b_{\mathrm{d}}}{\partial t}=D_{\text {bio }} \frac{\partial^{2} b_{\mathrm{d}}}{\partial x^{2}}-w \frac{\partial b_{\mathrm{d}}}{\partial x}+k_{\text {trans }}\left(1+K_{\text {ads }}\right) b_{\mathrm{s}} \\
& -\left(k_{\text {death }}+k_{\text {graze }}+k_{\text {act }}\right) b_{d}
\end{aligned}
$$




\section{THE ANALYSIS}

In order to address the question of the existence of a biomass-carbon relation, neither Eq. (15) nor Eq. (16) needs to be solved in any formal sense. Instead, an answer can be developed simply by considering which terms dominate the balance in each equation; by this, I mean that the terms in these equations are not of equal numerical size, which indicates that some terms/processes are more important than others in achieving the stated balance.

The object of the analysis that follows is to discover the relative size of the terms and to establish rigorously which terms could be neglected to the lowest order of accuracy. This process of finding the relative magnitude of terms in an equation is called scaling. To paraphrase Lin \& Segel (1974), scaling attempts to select reference quantities so that introduction of these quantities into each term in the dimensiona! equations transforms it into the product of a constant dimensional factor (usually a parameter grouping), which estimates the term's actual order of magnitude, and a function of dimensionless variable(s) of unit order of magnitude. This is somewhat different than the usual meaning of scaling used in biological sciences (e.g. Schmidt-Nielsen 1984), but it is not totally unrelated.

The depth variable $x$ is scaled by the total depth interval of interest, $L$. Microbial populations exhibit large changes on depth scales of $10 \mathrm{~cm}$ (e.g. Rublee 1982, Novitski \& Karl 1986, Novitski 1987), and this is chosen as the value for $L$. Dividing $x$ by $L$ produces a new dimensionless depth variable (coordinate), $\xi \equiv$ $x / L$. The time variable, $t_{\mathrm{t}}$ is scaled by the time, $t_{\mathrm{m}}$, it takes for the microbes to move over the interval depth $L$. The diffusionlike transport processes of bioturbation, Brownian motion and motility will produce a $t_{\mathrm{m}}$ of

$$
t_{\mathrm{m}}=\frac{L^{2}}{\left(D_{\mathrm{bio}}+D_{\mathrm{bm}}+\theta D_{\mathrm{mo}}\right)}
$$

which results in a value of about 3 yr with the parameter values in Table 1 . By comparison, the time to bury (advect) microbes over this distance is certainly no less than $10 \mathrm{yr}$ if the sediment accumulates at an atypical rate of $1 \mathrm{~cm} \mathrm{yr}^{-1}$ and no less than $100 \mathrm{yr}$ for more reasonable accumulation rates. Consequently, Eq. (18) defines the appropriate value of $t_{\mathrm{m}}$ and division of $t$ by $t_{\mathrm{m}}$ produces a new dimensionless time variable, $\tau \equiv$ $t / t_{\mathrm{m}}$. Finally, the biomass concentrations $b_{\mathrm{s}}$ and $b_{\mathrm{d}}$ are scaled with their values at the sediment-water interface, $\left(b_{s}\right)_{0}$ and $\left(b_{d}\right)_{0}$ and the concentration of the reactive organic carbon is also scaled with the concentration at this surface, $g_{0}$. The new nondimensional concentrations are then $B_{\mathrm{s}} \equiv b_{\mathrm{s}} /\left(b_{\mathrm{s}}\right)_{0}, B_{\mathrm{d}} \equiv b_{\mathrm{d}} /\left(b_{\mathrm{d}}\right)_{0}$, and $G \equiv g / g_{0}$.
Substitution of these scales and new variables, and some simple re-arrangement, produces the following 2 equations:

$$
\begin{aligned}
& \frac{\partial B_{\mathrm{s}}}{\partial \tau}=\frac{\partial^{2} B_{\mathrm{s}}}{\partial \xi^{2}}-\frac{\theta D_{\mathrm{ct}}}{\left(D_{\mathrm{bm}}+D_{\mathrm{bio}}+\theta D_{\mathrm{mo}}\right)} \frac{\partial}{\partial \xi}\left(\frac{B_{\mathrm{s}}}{G} \frac{\partial G}{\partial \xi}\right) \\
& -\frac{w L}{\left(D_{\mathrm{bm}}+D_{\mathrm{bio}}+\theta D_{\mathrm{mo}}\right)} \frac{\partial B_{\mathrm{s}}}{\partial \mathrm{x}} \\
& +\frac{y k_{\mathrm{het}} L^{2}}{\left(1+\mathrm{K}_{\mathrm{ads}}\right)\left(D_{\mathrm{bm}}+D_{\mathrm{bio}}+\theta D_{\mathrm{mo}}\right)} \frac{g_{\mathrm{o}}}{\left(b_{\mathrm{s}}\right)_{\mathrm{o}}} G \\
& +\frac{k_{\mathrm{act}} L^{2}}{\left(D_{\mathrm{bm}}+D_{\mathrm{bio}}+\theta D_{\mathrm{mo}}\right)} \frac{\left(b_{\mathrm{d}}\right)_{\mathrm{o}}}{\left(b_{\mathrm{s}}\right)_{\mathrm{o}}} B_{\mathrm{d}} \\
& +\frac{\left(k_{\mathrm{photo}} I-k_{\mathrm{death}}-k_{\mathrm{graze}}-k_{\mathrm{trans}}\right) L^{2}}{\left(D_{\mathrm{bm}}+D_{\mathrm{boo}}+\theta D_{\mathrm{mo}}\right)} B_{\mathrm{s}} \\
& -\frac{K_{\mathrm{ads}} k_{\text {irrig }} L^{2}}{\left(1+K_{\mathrm{ads}}\right)\left(D_{\mathrm{bm}}+D_{\mathrm{blo}}+\theta D_{\mathrm{mo}}\right)} B_{\mathrm{s}}
\end{aligned}
$$

and

$$
\begin{aligned}
& \frac{\partial B_{\mathrm{d}}}{\partial \tau}=\frac{D_{\mathrm{bio}}}{\left(D_{\mathrm{bm}}+D_{\mathrm{bio}}+\theta D_{\mathrm{mo}}\right)} \frac{\partial^{2} B_{\mathrm{d}}}{\partial \xi^{2}} \\
& -\frac{w L}{\left(D_{\mathrm{bm}}+D_{\mathrm{b} 10}+\theta D_{\mathrm{mo}}\right)} \frac{\partial B_{\mathrm{d}}}{\partial \xi} \\
& +\frac{k_{\mathrm{trans}}\left(1+K_{\mathrm{ads}}\right) L^{2}}{\left(D_{\mathrm{bm}}+D_{\mathrm{b} 10}+\theta D_{\mathrm{mo}}\right)} \frac{\left(b_{\mathrm{s}}\right)_{\mathrm{o}}}{\left(b_{\mathrm{d}}\right)_{\mathrm{o}}} B_{\mathrm{s}} \\
& -\frac{\left(k_{\text {death }}+k_{\mathrm{graze}}+k_{\mathrm{act}}\right) L^{2}}{\left(D_{\mathrm{bm}}+D_{\mathrm{blo}}+\theta D_{\mathrm{mo}}\right)} B_{\mathrm{d}}
\end{aligned}
$$

These last 2 equations are now scaled, as defined above, i.e. each term is a product of a parameter/parameter grouping (including unity) and a dimensionless variable or derivative.

The last step of the analysis is to substitute actual values for all the parameters in Eqs. (19) \& (20). Most of these are in Tables $1 \& 2$, with the exception $K_{a d s}, \theta$, and the ratios of the initial concentrations. As explained above, $K_{\text {ads }}$ is a small number and its exact value is essentially immaterial to the following results; without great prejudice, its value can be set to zero. The mobile fraction $\theta$ has also been argued to be small, but this paper's conclusion remains unaltered even if it is set to its maximum possible value of 1 . Finally the ratio $\left(b_{s}\right)_{0} /\left(b_{\mathrm{d}}\right)_{0}$ is a small number, say 0.1 , if the microbial population is mostly inactive with respect to growth, as advanced by Novitski (1987); conversely, the ratio $g_{0} /\left(b_{s}\right)_{0}$ is a large number, as the live biomass is normally a small fraction of the concentration of total organic matter in sediments. This ratio is set to a maximum value of 0.1 ; smaller values will only reinforce the conclusions. Substituting all values produces the following order-of-magnitude balance for surface-active biomass, 


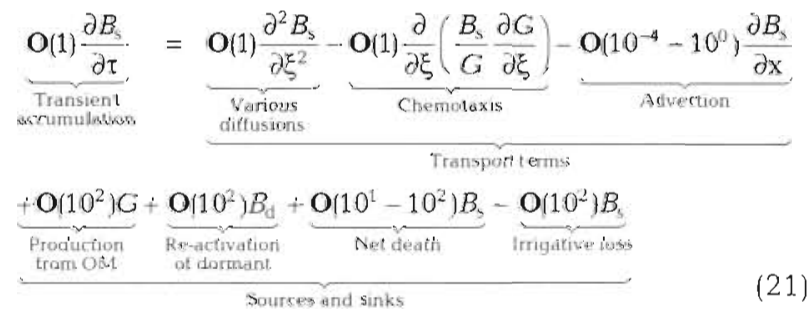

and for dormant biomass,

$$
\begin{aligned}
& \underbrace{\mathrm{O}(1) \frac{\partial B_{\mathrm{d}}}{\partial \tau}}_{\begin{array}{c}
\text { Transient } \\
\text { accumulation }
\end{array}}=\underbrace{\mathbf{O}\left(10^{-3}-10^{0}\right) \frac{\partial^{2} B_{\mathrm{d}}}{\partial \xi^{2}}}_{\text {Transport terms }}-\underbrace{\mathbf{O}\left(10^{-4}-10^{0}\right) \frac{\partial B_{\mathrm{s}}}{\partial \xi}}_{\text {Advection }} \\
& \underbrace{\mathbf{O}\left(10^{1}\right) B_{\mathrm{s}}}_{\begin{array}{c}
\text { Various diffusions } \\
\text { free biomass }
\end{array}}-\underbrace{\begin{array}{c}
\text { Loss by death, grazing } \\
\text { and activation }
\end{array}}_{\text {Sources ard sinks }}
\end{aligned}
$$

respectively, for Eqs. (19) \& (20), and where the symbol $O$ (number) indicates the size of the coefficient that multiplies the adjoining term, e.g. $\mathbf{O}\left(10^{-2}\right)$ means a term of magnitude 0.01 (dimensionless). The $\mathbf{O}$ (number) symbols have a one-to-one correspondence with the parameter groupings at the begining of each term in Eqs. (19) \& (20). When a range rather than a number is found in the $\mathbf{O}$ () symbol, this indicates that the parameter grouping has a large possible range based on the values quoted in Tables $1 \& 2$.

Examination of the components of Eq. (21) shows that the source-sink terms constitute the lowest order balance and that the transport and transient accumulation terms are next order (smaller) corrections to that balance, i.e. we could write Eq. (16) as:

$$
\begin{aligned}
& \left(k_{\text {death }}+k_{\text {graze }}+k_{\text {trans }}+\frac{K_{\text {ads }} k_{\text {irrig }}}{1+K_{\text {ads }}}-k_{\text {photo }} I\right) b_{\mathrm{s}}-k_{\text {act }} b_{\mathrm{d}} \\
& =\frac{y k_{\text {het }}}{1+K_{\text {ads }}} g+\sigma_{1}(x, t)
\end{aligned}
$$

where $\sigma_{1}(x, t)$ is a correction term that accounts for the effects of transport and temporal variations as found in Eq. (16), i.e. all the terms in Eq. (21) multiplied by $\mathbf{O}(1)$ and smaller, $\sigma_{1}(x, t)$ is not only a function of $x$ and $t$, but also $b_{\mathrm{s}}$ and its spatial and temporal derivatives, as dictated by the full balance in Eq. (16). The preceding analysis would argue that this latter correction is, nevertheless, small. Likewise, Eq. (22) suggests that, to the lowest order of accuracy,

$$
b_{\mathrm{s}}=\frac{\left(k_{\text {death }}+k_{\text {graze }}+k_{\mathrm{act}}\right)}{k_{\text {trans }}\left(1+K_{\mathrm{ads}}\right)} b_{\mathrm{d}}+\sigma_{2}(x, t)
$$

where $\sigma_{2}(x, t)$ is another transport-transient correction term, again relatively small in magnitude. Substitution of Eq. (24) into Eq. (23) generates the equation

$$
\alpha b_{\mathrm{d}}=\beta g+\sigma_{3}(x, t)
$$

where $\sigma_{3}(x, t)$ is a relatively small, combined, transporttransient correction term,

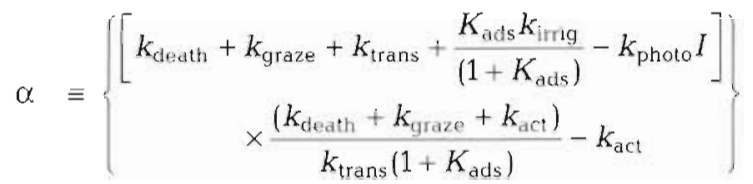

and

$$
\beta \equiv \frac{y k_{\text {het }}}{1+K_{\text {ads }}}
$$

The correlation advanced by Rublee (1982) is based upon total organic carbon and total cell numbers; this latter quantity can be converted to mass concentration by using a nominal bacterial size and density to biomass, while accepting the probable imprecisions of such a calculation. On the other hand, Eq. (25) established a lowest order link between the metabolically inactive biomass, $b_{\mathrm{d}}$, and the labile organic matter, $g$. Fortunately, according to Novitski (1987), most of the biomass is inactive in sediments, so that $b_{\mathrm{d}}$ is a good approximation of total biomass, $b_{\mathrm{T}}$, i.e.

$$
b_{\mathrm{d}}=b_{\uparrow}
$$

Furthermore, total organic matter, $g_{T}$, can be expressed as the sum of the labile, $g$, and refractory, $g_{r}$ components,

$$
g_{\mathrm{T}}=g+g_{\mathrm{r}}
$$

Substitution of Eqs. (28) \& (29) into Eq. (25) produces the final result:

$$
b_{\mathrm{T}} \approx \frac{\beta}{\alpha} g_{\Upsilon}+\sigma_{4}(x, t)
$$

where $\sigma_{4}(x, t)$ is yet another correction term that includes the added effects of the refractory component on the relation, as well as the effects of transport processes and transients.

Eq. (30) establishes a linear (lowest order) relation between organic matter and microbial biomass concentration, in agreement with the findings of Rublee (1982). Best fits to any data may still be colored by the potential artifact identified by Bird \& Duarte (1989), but the existence of the linear correlation is now estahlished. Nevertheless, the factor $\sigma_{4}(x, t)$ in Eq. (30) is not a constant (as in Rublee 1982), but a complex function of space, time, the derivatives of the active and inactive biomasses and the refractory organic matter concentration. A linear regression, as in Rublee (1982), approximates the effects of $\sigma_{4}(x, t)$ as a single constant, i.e. its mean value for all the sediment locations and depth intervals included in his data base. Rublee's linear fit explained only $63 \%$ of the variability in his data, and part of the reason is the approximation of $\sigma_{4}(x, t)$ as a constant. The take-home message here is not that 
Rublee's particular relation is necessarily universal, simply that exploration of this type of data by means of linear regression appears to be a theoretically justified approach.

To this author's knowledge, Eqs. (13) to (15) represent collectively the first mathematical balance model for microbial biomass in aquatic sediments. While the application presented here has been rather modest, the use of such equations in engineering and hydrological problems has proven to be fruitful, and the same may be true for the study of early diagenetic problems.

Acknowledgements. This research was supported by a Research (Operating) Grant from the Natural Sciences and Engineering Research Council of Canada. The author wishes to thank 2 anonymous reviewers for their helpful comments.

\section{LITERATURE CITED}

Aller RC (1982) The effects of macrobenthos on chemical properties of marine sediment and overlying water. In: McCall PL, Tevesz MJ (eds) Animal-sediment relations. Plenum, New York, p 53-102

Aller RC (1988) Benthic fauna and biogeochemical processes in marine sediments: the role of burrow structures. In: Blackburn TH, Sorensen J (eds) Nitrogen cycling in coastal marine environments. John Wiley and Sons, New York, p 301-338

Bazin MJ, Saunders PT, Prosser Ji (1976) Models of microbial interactions in the soil. CRC Crit Rev Microbiol 4:463-498

Berg HC (1993) Random walks in biology, expanded edition. Princeton University Press, Princeton, NJ

Berner RA (1971) Principles of chemical sedimentology. McGraw-Hill, New York

Berner RA (1980) Early diagenesis. A theoretical approach. Princeton University Press, Princeton, NJ

Bird DF, Duarte CM (1989) Bacterial-organic matter relationship in sediments: a case of spurious correlation. Can J Fish Aquat Sci 46:904-908

Blackburn TH (1987) Microbial food webs in sediments. In: Sleigh MA (ed) Microbes in the sea. Ellis Harwood, Chichester, p 39-58

Blanch HW (1981) Invited review: microbial growth kinetics. Chem Eng Commun 8:181-221

Boudreau BP (1984) On the equivalence of nonlocal and radial-diffusion models for porewater irrigation. J Mar Res 42:731-735

Boudreau BP (1992) A kinetic model for microbic organicmatter decomposition in marine sediments. FEMS Microbivi Ecoil $102: \hat{1}-14$

Boudreau BP (1997) Diagenetic models and their implementation. Springer-Verlag, Berlin

Carberry JJ (1976) Chemical and catalytic reaction engineering. McGraw-Hill, New York

Corapcioglu MY, Haridas A (1984) Transport and fate of microorganisms in porous media: a theoretical investigation. J Hydrol 72:149-169

Corapcioglu MY, Haridas A (1985) Microbial transport in soils and groundwater: a numerical model. Adv Wat Resour 8: $188-200$

Dale NG (1974) Bacteria in intertidal sediments: factors related to their distribution. Limnol Oceanogr 19:509-51.8
Gaudy AF, Gaudy ET (1972) Mixed microbial populations. Adv Biochem Eng 2:97-143

Hattori T, Hattori R (1976) The physical environment in soil microbiology: an attempt to extend principles of microbiology to soil microorganisms. CRC Crit Rev Microbiol 4: $423-461$

Hino M (1981) Ecohydrodynamics. Adv Hydrosci 12:143-193

Humphrey AE (1972) The kinetics of biosystems: a review. In: Gould RF (ed) Chemical reactor engineering. Am Chem Soc Symp Ser 109:630-650

Lauffenburger DA (1983) Effects of cell motility properties on cell populations in ecosystems. In: Blanch HW, Papoutsakis T. Stephanopoulos G (eds) Foundations of biochemical engineering: kinetics and thermodynamics in biological systems. Am Chem Soc Symp Ser 207: 265-292

Lauffenburger D, Aris R, Keller KH (1981) Effects of random motility on growth of bacterial populations. Microb Ecol 7 : $207-227$

Lerman A (1977) Migrational processes and chemical reactions in interstitial waters. In: Goldberg ED, MCCave IN, O'Brien JJ, Steele JH (eds) The sea: ideas and observations on progress in the sludy of the seas, Vol 6. WileyInterscience, New York, p 695-738

Lerman A (1978) Chemical exchange across sediment-water interface. Annu Rev Earth Planet Sci 6:281-303

Lerman A (1979) Geochemical processes: water and sediment environments. Wiley Interscience, New York

Lin CC, Segel LA (1974) Mathematics applied to deterministic problems in the natural sciences. Macmillan, New York

Linley EAS, Newell RC (1984) Estimates of bacterial growth yields based on plant detritus. Bull Mar Sci 35:409-425

Lovely PS, Dahlquist FW (1975) Statistical measures of bacterial motility and chemotaxis. J Theor Biol 50:477-496

Nealson KH (1997) Sediment bacteria: who's there, what are they doing, and what's new? Annu Rev Earth Planet Sci $25: 403-434$

Novitsky JA (1987) Microbial growth rates and biomass production in a marine sediment: evidence for a very active but mostly nongrowing community. Appl Environ Microbiol 53:2368-2372

Novitsky JA, Karl DM (1986) Characterization of microbial activity in the surface layers of a coastal sub-tropical sediment. Mar Ecol Prog Ser 28:49-55

Okubo A (1980) Diffusion and ecological problems: mathematical models. Biomathematics Vol 10, Springer-Verlag, Berlin

Rosen G (1983) Theoretical significance of the condition $\delta=$ $2 \mu$ in bacterial chemotaxis. Bull Math Biol 45:151-153

Rublee PA (1982) Bacterial and microbial distribution in estuarine sediments. In: Kennedy VS (ed) Estuarine comparisons. Academic Press, New York, p 159-182

Schmidt-Nielsen K (1984) Scaling. Why is animal size so

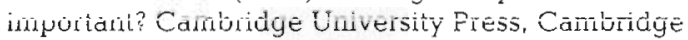

Segel LA, Chet I, Henis Y (1977) A simple quantitative assay for bacterial mobility. J Gen Microbiol 98:329-337

Tan Y, Bond WJ (1995) Modeling subsurface transport of microorganisms. In: Singh VP (ed) Environmental hydrology. Kluwer Academic Publishers, Dordrecht, p 321-355

Thibodeaux LJ (1996) Chemodynamics. Environmental movement of chemicals in air, water and soil. John Wiley and Sons, New York

Van Cappellen P, Gaillard JF (1996) Biogeochemical dynamics in aquatic sediments. Rev Mineral 34:335-376

Van Cappellen P, Ciaillard JF, Rabouille C (1993) Biogeochemical transformations in sediments: kinetic models of 
early diagenesis. In: Wollast $\mathrm{R}$, Chou L, Mackenzie $\mathrm{F}$ (eds) Interactions of $\mathrm{C}, \mathrm{N}, \mathrm{P}$ and $\mathrm{S}$ biogeochemical cycles. NATO-ARW, Springer-Verlag, Berlin, p 401-445 Westrich JT, Berner RA (1984) The role of sedimentary

Editorial responsibility: Gary King, Walpole, Maine, USA organic matter in bacterial sulfate reduction: the G model tested. Limnol Oceanogr 29:236-249

Williams FM (1971) Dynamics of microbial populations. Syst Anal Sim Ecol 1:197-267

Submitted: April 1, 1998; Accepted: September 1, 1998

Proofs received from author(s): April 22, 1999 